\title{
Design and Construction of Microcontroller Based Charge Controller for Photovoltaic Application
}

\author{
${ }^{1}$ F. Sani, ${ }^{2}$ H.N Yahya, ${ }^{1}$ M. Momoh, ${ }^{1}$ I.G. Saidu and ${ }^{1}$ D.O. Akpootu \\ ${ }^{I}$ Department of Physics, Usmanu Danfodiyo University Sokoto, Nigeria \\ ${ }^{2}$ Sokoto Energy Research Center, Sokoto, Nigeria.
}

\begin{abstract}
This paper describes a microcontroller based charge controller using PWM (pulse width modulation) technique. This PWM technique is employed by the PIC16F877 microcontroller. The microcontroller is to charge a $12 \mathrm{~V}$ battery using $80 \mathrm{~W}$ solar panel. The main feature of this charge controller is dusk to dawn operation; it switches 'on' the load (the light) at dusk (evening) and switches off at dawn (morning). During day time, the load is disconnected from the battery and the battery is to be recharged with current from the solar panel. When the battery is at full charge (14.7V), the charging current becomes "pulsed" interrupted by the PIC16F877. "Battery Full" will be displayed on the liquid crystal display (LCD). An inbuilt analog to digital converter $(A D C)$ is used to determine voltage level of the battery and the solar panel voltage. The hardware design, software implementation, and flow chart of the program are also discussed in this paper. Keywords: Charge controller, battery, microcontroller, pulse width modulation, photovoltaic.
\end{abstract}

\section{Introduction}

As the source of conventional energy deplete day by day, resorting to alternative sources, energy like solar energy has become the need of the hour. Solar energy can be used to generate power in two-ways; solar thermal conversion and solar electric (photovoltaic) conversion. Solar thermal is employed in heating of fluids to produce steam to derive turbines for large scale centralized generation while solar electric (photovoltaic) which is considered in this paper, is the direct conversion of sunlight into electricity through photocells. Photovoltaic (PV) production becomes double every two years, increasing by an average of 48 percent each year since 2002 [2]. For this reason, it has become the world's fastest growing energy technology [4].

A charge controller is an essential part of nearly all power systems that charge batteries, whether the power source is PV, wind, hydro e.tc [3]. A PV system consists of a PV array which converts sunlight to direct - current electricity, a control system which regulates the battery charging and operation of the load, energy storage in the form of secondary batteries and loads. A charge controller is one of the functional and reliable components of PV system. The main function of a charge controller in a PV system is to keep batteries properly charged and safe for the long term, and to protect it from deep discharging [3], without a charge controller, the battery will overcharge. Absence of charge controller in PV system results in high maintenance cost including frequent battery replacement. Hence, a charge controller is important to prevent battery overcharging excessively, over discharging, reverse current flow at night and to prolong the life of the batteries in a PV system [3].

When a lead acid battery is charged, its voltage rises. When the charge current is first turned on, the internal resistance of the battery resists the current, and the voltage immediately rises above the open circuit voltage. Towards the end of charge, the voltage rises sharply as the battery begins to "gas". "Gassing" is the decomposition of the liquid water into hydrogen and oxygen gasses, and also called "electrolysis" [1]. If gassing is left to continue for a long period of time, the battery is overcharged, resulting in accelerated corrosion of the battery plates, loss of electrolyte, and physical damage of the plates.

The aim of this paper is to design and construct a microcontroller based charge controller for PV application, capable of charging a $12 \mathrm{~V}$ battery using $80 \mathrm{~W}$ solar panel. The hardware and software design are adopted.

\section{Hardware design}

\section{Materials And Methods}

In this study, we minimize components count using a programmable PIC microcontroller for all the switching actions of the lighting system. The system design is based on the block diagram shown in figure 1 . The detail design procedures are then presented in each of the block. 


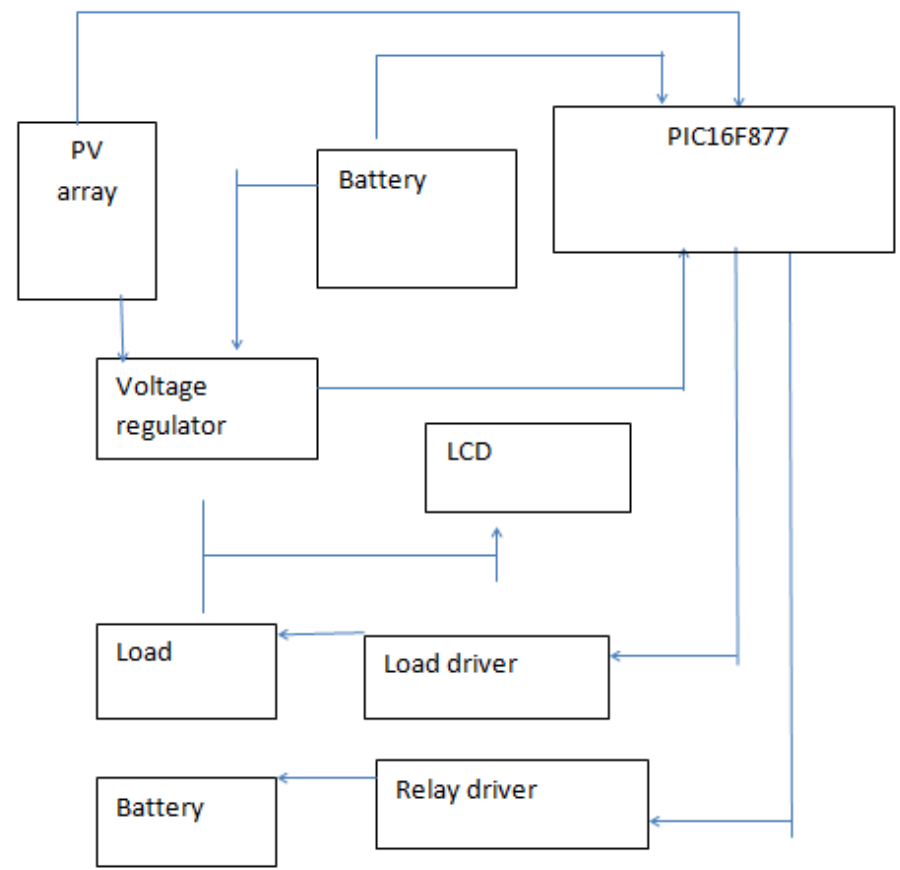

\section{Software design}

Figure 1: Block diagram of the system

The microcontroller operated according to the program written inside its memory. The main objective of the program is to give instruction, control and coordinate the PIC16F877 to execute various tasks, such as to control battery voltage. Control has been developed according to flow chart shown in figure 2.The chart represents the software development algorithm. Based on this chart a program was developed in $\mathrm{C}-$ language and debugged. The software program was then loaded into the PIC16F877 using a PIC programmer.

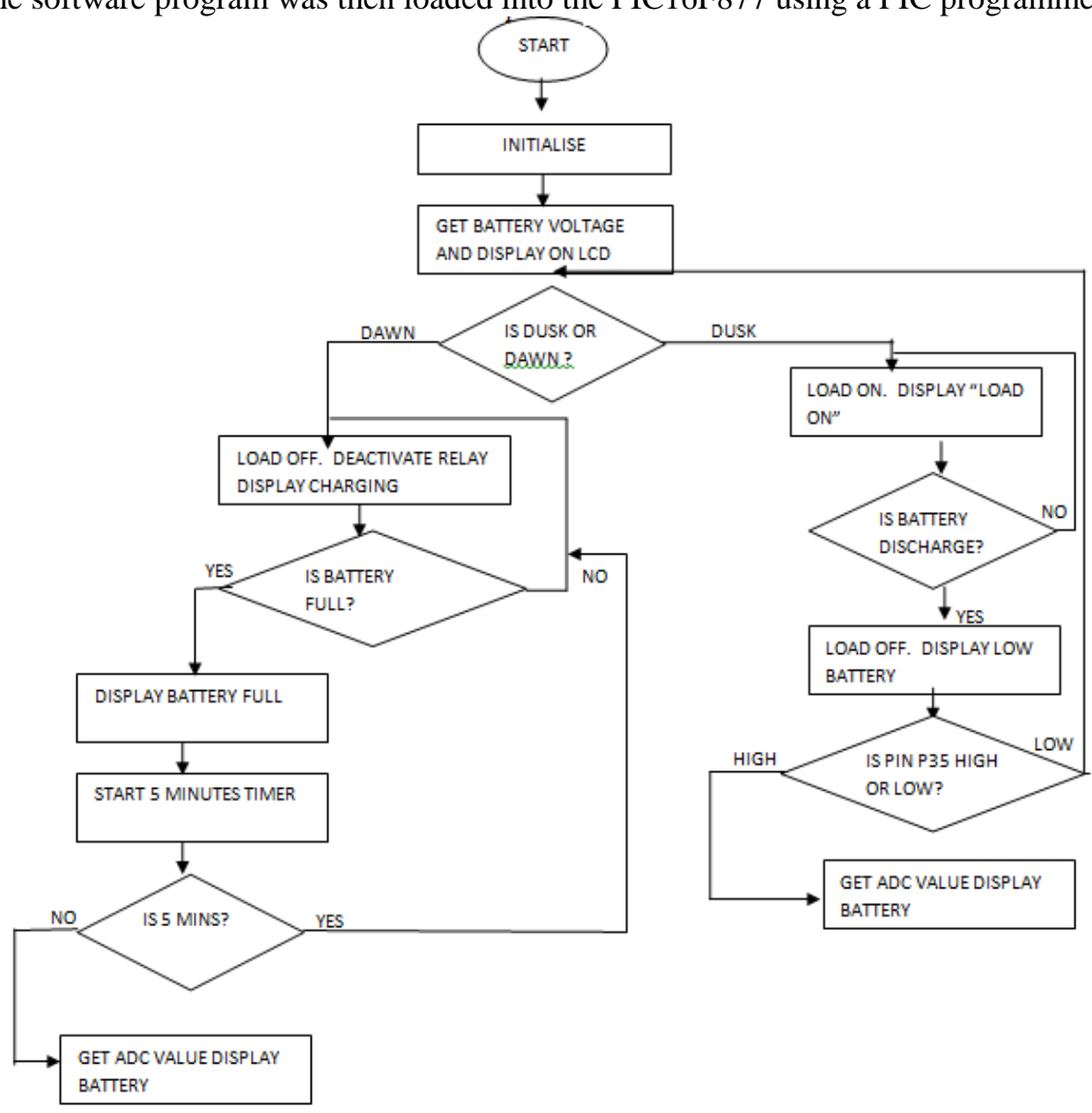




\section{System modeling}

After power on, using switch SW, the microcontroller reads the battery voltage with the help of inbuilt ADC and displays the charging condition of the battery on LCD. It monitors the input signal of the ADC and activate the load or charging Relay $\mathrm{RL}_{1}$.

$+5 \mathrm{~V}$ is used as Vref of the ADC, the output voltage of the ADC should not exceed $+5 \mathrm{~V}$. A potential divider is used at pin 2 and pin 4 of the microcontroller using resistors $R_{2}, R_{3}, R_{4}, R_{5}, R_{6}$, and $R_{7}$ to scale down the voltage from $0 \mathrm{~V}-5 \mathrm{~V}$. When the solar panel voltage is present, the current flows from the solar module throgh diode $\mathrm{D}_{1}$. The diode is preventing back currents flowing from the battery to the solar panel. The microcontroller activate the relay $\mathrm{RL}_{1}$ connecting the solar panel to the battery through a transistor $\mathrm{Q}_{2}$ and diode $\mathrm{D}_{3}$. The diode $\mathrm{D}_{3}$ helps dampen transient spikes that can be generated by the relay's coil. The battery will continue charging, to full charge $(14.7 \mathrm{~V})$. When the battery is fully charged the microcontoller interrupts the charging current and start 5 - minute timer. At this stage "Batteryy full" will be displayed on LCD based on the regulator $\mathrm{U}_{2}$ which regulated the constant voltage value to be used by the PIC and the LCD. Diode $\mathrm{D}_{4}$ protect reverse of the regulated voltage back to the battery. Capacitors $C_{1}$ and $C_{2}$ at the output and input of the 7805 regulator $\mathrm{U}_{2}$ are used as ripple rejection and also to prevent debouncing of the switch. Atimes the switch cannot make smooth and clean contact but rather oscillate between low and high until settle, such oscillation will be prevented by the capacitors.

In the absent of solar radiation, the microcontroller senses this through ADC and activate the load by switching on MOSFET $Q_{1}$ via a transistor $\mathrm{Q}_{3}$ from pin 33 of the microcontroller and "load on" message as well as the battery's voltage are displayed on the LCD. In this mode, the microcontroller monitors for low battery. When the battery voltage drops below 9.4Volt the microcontroller turns off MOSFET Q1 and "Battery low" message is dispalyed. Figure 3 shows the circuit of the microcontroller based charger.

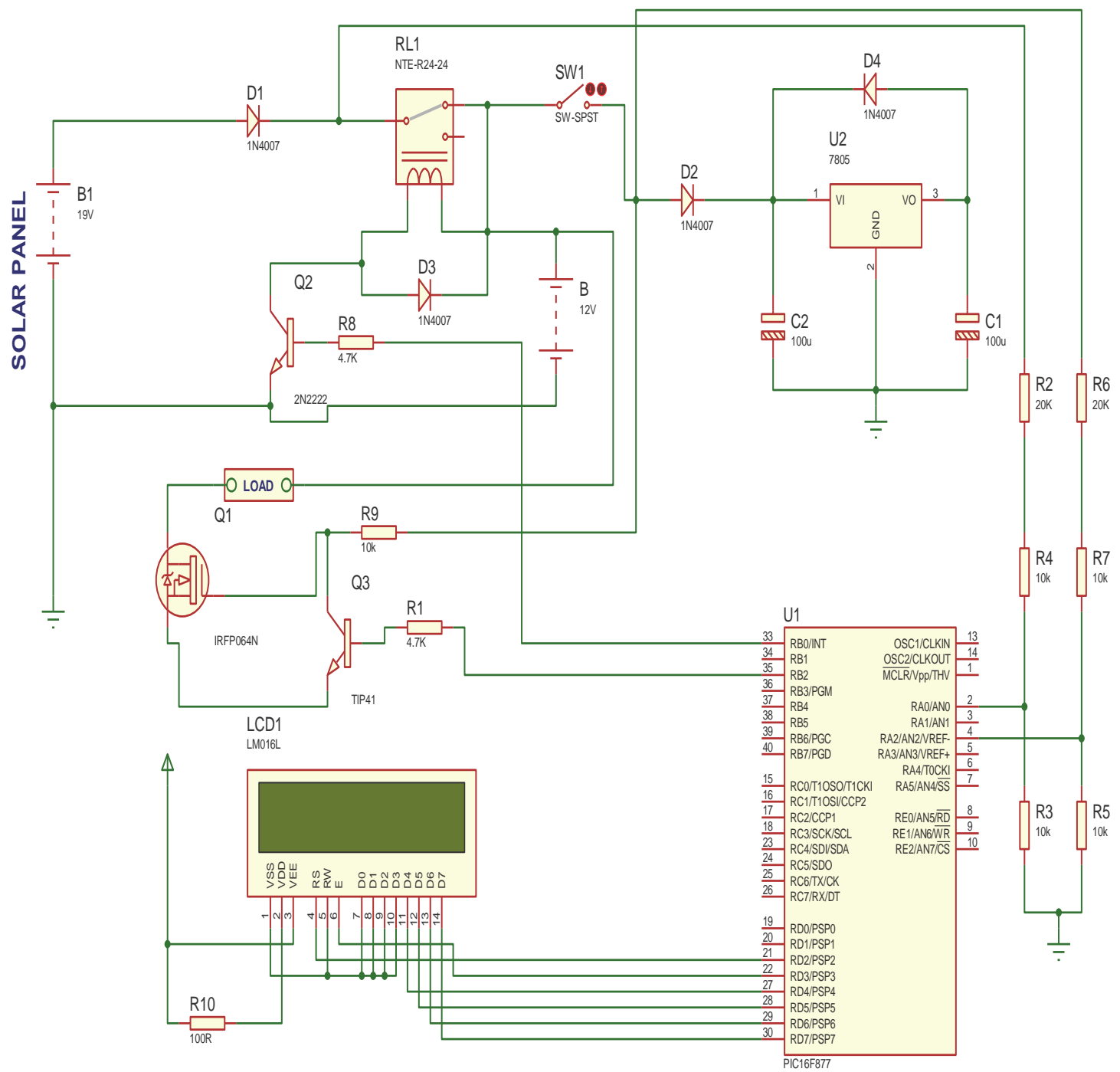

Figure 3: Circuit of the microcontroller based charger 
The complete list of the components used is shown in table 1.

Table 1: List of the components used

\begin{tabular}{|l|l|l|l|}
\hline S/N & Component & Quantity & Value \\
\hline 1 & Resistor & 5 & $10 \mathrm{k}$ \\
\hline 2 & Resistor & 2 & $20 \mathrm{k}$ \\
\hline 3 & Resistor & 2 & $4.7 \mathrm{k}$ \\
\hline 4 & Resistor & 1 & $100 \Omega$ \\
\hline 5 & Capacitor & 2 & $100 \mu \mathrm{F}$ \\
\hline 6 & Diode & 3 & IN4007 \\
\hline 7 & Relay & 1 & NTE-R24-24 \\
\hline 8 & Transistor & 2 & $2 \mathrm{~N} 2222 \mathrm{~A}$ \\
\hline 9 & MOSFET & 1 & IRFP064N \\
\hline 10 & LCD & 1 & LM 016L \\
\hline 11 & Switch & 1 & SW-SPST \\
\hline 12 & Microcontroller & 1 & PIC16F877 \\
\hline 13 & Voltage Regulator & 1 & 7805 \\
\hline
\end{tabular}

\section{Charging test}

\section{Results And Discussion}

The test was conducted at the PV demonstration room, Sokoto Energy Research Centre (SERC) on March 7, 2013 from exactly 7:00AM to 13:30PM. In conducting the charging test, 80W solar module (LM08OAAOO), was used to provide charging voltage. A digital multimeter was used to measure the initial voltage of the battery as well as solar panel voltage. Another digital meter was connected across the solar module to measure the solar panel current. With the connection completed, the charge controller was switched on. A message reading "charging" as well as the battery voltage were displayed on the LCD.

The solar panel voltage charging voltage were noted and recorded at the beginning of the charging experiment. Subsequently, the values were recorded after every 30 minutes interval. All the values obtained were then tabulated. The experiment continued until the battery became fully charged. At this point the LCD displayed "Battery full".

The result obtained during charging test is presented in table 2. The measured parameters included among others, battery voltage $\left(\mathrm{V}_{1}\right)$, PV array voltage $\left(\mathrm{V}_{2}\right)$, PV array current $(\mathrm{I})$ and LCD voltage $\left(\mathrm{V}_{3}\right)$. The data were taken at 30 minutes interval. The result is tabulated in table 2.

Table 2: Charging test result

\begin{tabular}{|c|c|c|c|c|c|c|}
\hline Time $(\min )$ & $\mathrm{V}_{1}(\mathrm{~V})$ & $\mathrm{V}_{2}(\mathrm{~V})$ & $\mathrm{I}(\mathrm{A})$ & $\mathrm{V}_{3}(\mathrm{~V})$ & Load & Status \\
\hline 7:00 AM & 13.01 & 13.67 & 0.02 & 12.9 & Off & Charging \\
\hline 8:00AM & 13.14 & 13.02 & 0.33 & 13.1 & Off & Charging \\
\hline 9:00AM & 13.35 & 14.19 & 0.69 & 13.04 & Off & Charging \\
\hline 9:30AM & 13.48 & 14.48 & 1.56 & 13.16 & Off & Charging \\
\hline 10:00AM & 13.63 & 14.74 & 2.54 & 13.9 & Off & Charging \\
\hline 11:00AM & 13.90 & 14.99 & 2.48 & 14.2 & Off & Charging \\
\hline 11:30AM & 14.10 & 15.18 & 2.34 & 14.3 & Off & Charging \\
\hline 12:00PM & 14.29 & 15.34 & 12.18 & 14.5 & Off & Charging \\
\hline $12: 30 \mathrm{PM}$ & 14.42 & 15.47 & 2.05 & 14.6 & Off & Battery full \\
\hline 13:00PM & 14.51 & 15.53 & 1.95 & 14.7 & Off & Battery full \\
\hline 13:30PM & 14.50 & 15.49 & 1.70 & 14.7 & Off & Battery full \\
\hline
\end{tabular}

The charging test for the battery voltage as a function of time is shown in figure 4.

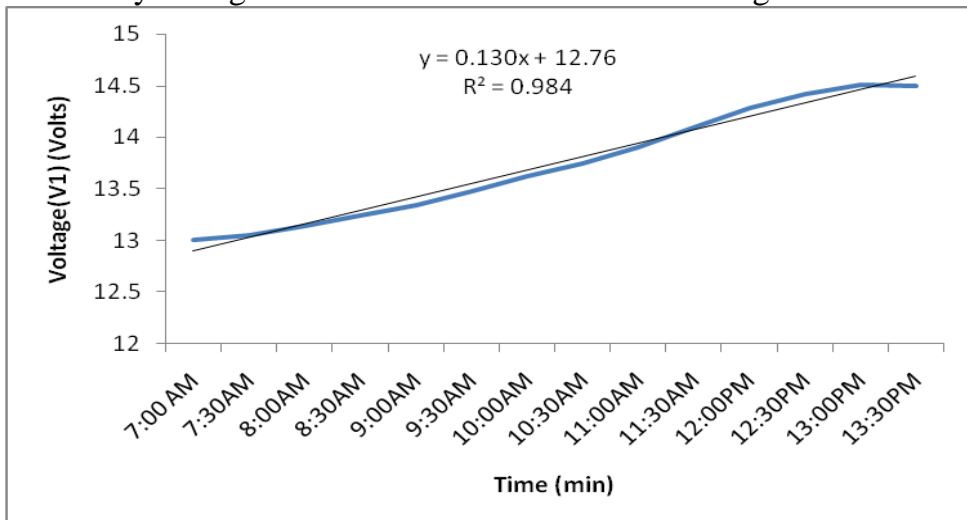

Figure 4: Charging test of battery voltage against time 


\section{Discharging test result}

The voltages for the discharging test were recorded after 15 minutes intervals. The parameters recorded are: battery voltage $\left(\mathrm{V}_{1}\right)$, LCD voltage $\left(\mathrm{V}_{2}\right)$ and load status. The results are tabulated in table 3 , while a plot of the discharging pattern is in figure 5.

Table 3: Discharging test result

\begin{tabular}{|l|l|l|l|}
\hline Time & $\mathrm{V}_{1}(\mathrm{~V})$ & $\mathrm{V}_{2}(\mathrm{~V})$ & Load status \\
\hline $2: 30 \mathrm{pm}$ & 12.5 & 12.2 & On \\
\hline $2: 45 \mathrm{pm}$ & 12.3 & 12.0 & On \\
\hline $3: 00 \mathrm{pm}$ & 12.1 & 11.9 & On \\
\hline $3: 15 \mathrm{pm}$ & 11.9 & 11.5 & On \\
\hline $3: 30 \mathrm{pm}$ & 11.1 & 10.9 & On \\
\hline $3: 45 \mathrm{pm}$ & 9.8 & 9.6 & On \\
\hline $4: 00 \mathrm{pm}$ & 9.5 & 9.4 & Off \\
\hline
\end{tabular}

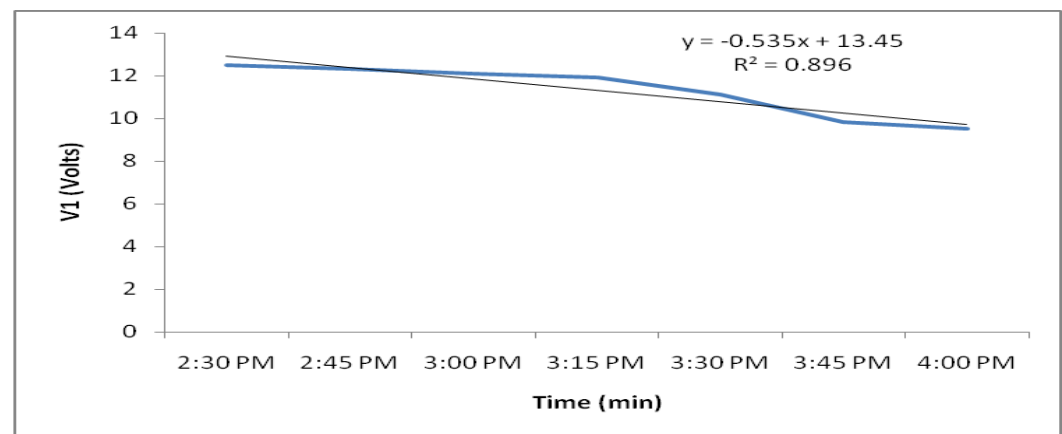

Figure 5: Discharging test graph

The results of charging and discharging gives high values of coefficient of determination, $\mathrm{R}^{2}$ this implies that the data excellently fit.

\section{Accuracy Test Result}

The accuracy test was deduced from charging test experiment. The result of the comparison of the standard digital voltmeter and that of the device is tabulated in the table 4. The parameters included are: Standard Digital Voltmeter Voltage $\left(\mathrm{V}_{1}\right)$ and the LCD Voltage $\left(\mathrm{V}_{2}\right)$.

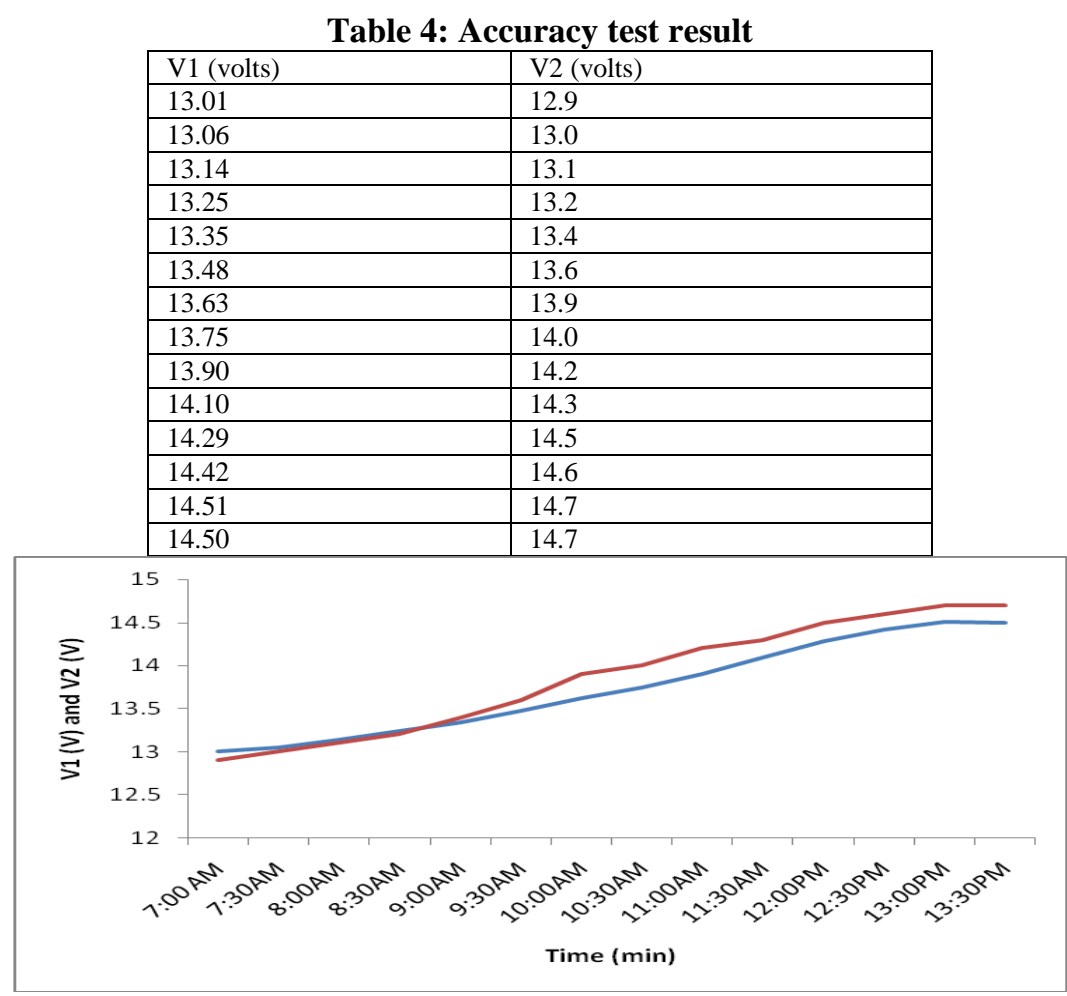

Figure 6: Accuracy test graph 
From table 2, it could be seen that the panel voltage was $13.67 \mathrm{~V}$ while that of the battery was $13.01 \mathrm{~V}$. This provides the potential difference necessary for the flow of current from the panel to the battery. At this point the LCD displayed the message "charging" and the value of the battery voltage while the load was switched off. This agreed with the design condition which stipulated that the charging takes place only during the day when there is no need for the lamp to be ON.

It is seen that the panel voltage increased steadily from 7:00AM with a value of $13.67 \mathrm{~V}$ and peaked at $13: 00 \mathrm{pm}$ with a value of $15.53 \mathrm{~V}$, it then decreased gradually to $15.49 \mathrm{~V}$ at $13: 30 \mathrm{pm}$. This is as expected as the sun shine hour of Sokoto is normally peaked around this time. The panel current which is a function of the solar radiation was also noted to rise gradually from $0.02 \mathrm{~A}$ at $7: 00 \mathrm{AM}$ to $2.05 \mathrm{~A}$ at around $12: 30 \mathrm{pm}$ then fall off gradually after then.

At 12:30PM, the charge controller displayed "Battery full" on the LCD and even though the solar panel was still connected, the displayed battery voltage remained steady at $14.7 \mathrm{~V}$ around 13:00pm and 13:30pm. The microcontroller has therefore interrupted the flow of charges from the solar panel to the battery thereby saving the battery from the harzadous effects associated with battery over charging. It was also noted that as long as there was voltage from the panel, the load remained off ensuring that power is not wasted during the day.

From table 3 , the voltage of the battery decreased gradually from a maximum value of $12.5 \mathrm{~V}$ to a minimum value of $9.5 \mathrm{~V}$. The LCD also displayed "Load on" during the process of discharging. The load went off immediately when the battery reached $9.5 \mathrm{~V}$. By so doing the charge controller ensured that the battery is not discharged too deep to damage it

The results obtained for voltage accuracy test as tabulated in table 4 show that there were small deviations between the two voltages. The measured voltages are therefore likely to have error of 0.05 to \pm 0.12 from the actual value. The possible reason for slight difference in the two measured voltages is that the output of the solar potential divider was rounded up to $5 \mathrm{~V}$. The ADC would read these voltages and convert them to an 8 bit number and ADC conversion involves quantization of the input, so it might introduced a small amount of error known as quantization error.

\section{Conclusion}

In Nigeria today, we have a very disturbing scenario where the cost of energy from the conventional source for generating electricity continues to increase and the need to turn to renewable energy like solar energy becomes the only viable and sustainable alternative or solution. The microcontroller based solar charge control technique presented in this paper prevents overcharging by reducing the flow of energy in to the battery when the battery approaches a full charge state.

During day time, the load is disconnected from the battery and the battery is to be recharged with the current from the solar panel. The microcontroller needs to know the presence of the solar panel to decide whether the load is to be connected or disconnected from the battery or whether the battery should be in charging mode or discharging mode. A simple sensor circuit is built using a potential divider. The relay $R L_{1}$ connects the solar panel to the battery through diode $\mathrm{D}_{1}$. This allows charging current from the panel to flow into the battery, when the battery reaches full charge the microcontroller interrupts the charging current.

In the absence of solar radiation, the microcontroller activates the load by switching on the MOSFET via a transistor. When the battery voltage drops to $9.5 \mathrm{~V}$, the microcontroller turns off the load to avoid overdischarge. The system displays the battery status on a liquid crystal display (LCD).

\section{References}

[1] Enric, P.U and Michael M.D (1998): Recommended Practices for Charge Controllers. Renewable Energy and Hybrid System Group CANMET Energy Diversification Research Laboratory.

[2] Gazi, S.M., Muhaiminul, I and Salim, K.M (2009): Design and Construction of Microcontroller Based Maximum Power Point PWM Charge Controller for Photovoltaic Application. Development in Renewable Energy Technology (2009) $1^{\text {st }}$ International Conference, Pp. 1-4.

[3] Jaya, N. I (2012): PIC Based Solar Charging Controller For Battery. International Journal of Engineering Science and Technology (IJEST), Pp 384

[4] Vikas, K. (2012): Microcontroller Based solar charge controller for power Application. International Journal of Electronics Communication and Computer Engineering. Volume 3, Issue 1. 